\section{Growth and Photosynthetic Capacity of Basil Grown for Indoor Gardening under Constant or Increasing Daily Light Integrals}

\author{
Elisa Solis-Toapanta ${ }^{1}$ and Celina Gómez ${ }^{1}$
}

ADDITIONAL INDEX WORDs. hydroponics, noncommercial production, Ocimum basilicum, pick-and-eat, sole-source lighting

SumMARY. In the quest to identify minimum daily light integrals (DLIs) that can sustain indoor gardening, we evaluated DLIs less than the recommended ranges for commercial production of basil (Ocimum basilicum). Experiments were conducted for 8 weeks to evaluate the effect of providing a constant vs. an increasing DLI over time $\left(\mathrm{DLI}_{\text {Inc }}\right)$ on growth and photosynthetic capacity of green ('Genovese Compact') and purple ('Red Rubin') basil grown hydroponically under a constant ambient temperature of $21^{\circ} \mathrm{C}$. Plants were grown under a $14 \mathrm{~h} \cdot \mathrm{d}^{-1}$ photoperiod and were subjected to the following DLI treatments: $4\left(\mathrm{DLI}_{4}\right), 6\left(\mathrm{DLI}_{6}\right), 8\left(\mathrm{DLI}_{8}\right)$, or $10\left(\mathrm{DLI}_{10}\right) \mathrm{mol} \cdot \mathrm{m}^{-2} \cdot \mathrm{d}^{-1}\left(80,119,159\right.$, and $197 \mu \mathrm{mol} \cdot \mathrm{m}^{-2} \cdot \mathrm{s}^{-1}$, respectively $) ; \mathrm{DLI}_{\text {Inc }}$ was used as a fifth treatment and was achieved by transitioning hydroponic systems systematically to treatments with greater DLIs every 2 weeks. In general, regardless of cultivar, leaf area, leaf number, and overall growth [shoot fresh weight (SFW) and shoot dry weight (SDW)] were similar for plants grown under $\mathrm{DLI}_{\text {Inc }}$ to $\mathrm{DLI}_{4}$ and $\mathrm{DLI}_{6}$ during weeks 2,4 , and 6 . However, plants grown under $\mathrm{DLI}_{\text {Inc }}$ produced the same leaf area as those grown under $\mathrm{DLI}_{10}$ at week 8 . Nonetheless, across weeks, growth was significantly less under $\mathrm{DLI}_{I_{n c}}$ compared with $\mathrm{DLI}_{10}$, but similar to that produced by $\mathrm{DLI}_{8}$ at week 8 . Photosynthetic responses were significant only at week 8 , for which leaves of plants grown under $\mathrm{DLI}_{8}, \mathrm{DLI}_{10}$, and $\mathrm{DLI}_{\mathrm{Inc}}$ had $15 \%$ to $25 \%$ greater maximum gross carbon dioxide $\left(\mathrm{CO}_{2}\right)$ assimilation $\left(A_{\max }\right)$ than plants grown under $\mathrm{DLI}_{4}$. The light saturation point of photosynthesis was unaffected by DLI, but showed a general increasing trend with greater DLIs. Overall, our results suggest that providing a constantly high DLI results in greater growth and yield than increasing the DLI over time. In addition, we found that changes in $A_{\text {max }}$ and the light saturation point are not good indicators of the capacity of whole plants to make use of the available light for photosynthesis and growth. Instead, morphological and developmental traits regulated by DLI during the initial stages of production are most likely responsible for the growth responses measured in our study.

$\mathrm{T}$ The increasing preference for living within city limits poses unique challenges for the continued development of productive green spaces. Indoor food gardening,

$\overline{\text { Received for publication } 26 \text { June 2019. Accepted for }}$ publication 26 Aug. 2019.

Published online 21 October 2019

${ }^{1}$ Environmental Horticulture Department, University of Florida, Institute of Food and Agricultural Sciences (IFAS), 1549 Fifield Hall, Gainesville, FL 32611-0670

Financial support was received from the U.S. Department of Agriculture (USDA) National Institute of Food and Agriculture, Multistate Research Project NE1835: Resource Optimization in Controlled Environment Agriculture. We thank the USDA-Agricultural Research Service Floriculture and Nursery Research Initiative \#58-3607-8-725, the Scotts Co., and industry partners of the Floriculture Research Alliance at the University of Florida (floriculturealliance.org) for supporting this research.

C.G. is the corresponding author. E-mail: cgomezv@ ufl.edu.

This is an open access article distributed under the CC BY-NC-ND license (https://creativecommons.org/ licenses/by-nc-nd/4.0/).

https://doi.org/10.21273/HORTTECH04442-19 which integrates edible production with indoor farming at a noncommercial scale, provides an opportunity to support the gardening experience for consumers with limited access to production resources such as space and fertile soil. According to an industry group, indoor food gardening is one of the fastest growing trends in horticulture (Garden Media Group, 2017). Compared with outdoor gardening in public spaces, indoor food gardening has received limited research attention despite its potential to help overcome common challenges affecting outdoor food gardening (e.g., unpredictable weather, weeds). In addition, indoor food gardening may increase access to fresh fruits and vegetables and can help foster a positive shift toward healthier food choices (Kalich et al., 2009; Kortright and Wakefield, 2011). Information is lacking to support small-scale indoor food gardening, as research-based recommendations for commercial indoor plant production typically aim to maximize productivity under optimal environmental conditions, which are difficult to replicate in an indoor environment designed for human comfort.

Consumers interested in indoor food gardening (from now on referred to as "indoor gardeners") tend to produce leafy greens (e.g., salad greens and microgreens) and culinary herbs, because they are fast-growing crops that require fewer inputs (e.g., fertilizer and water) and less maintenance compared with most fruiting crops (Di Gioia and Santamaria, 2015). Among them, basil is the most popular culinary herb because it can be cultivated for fresh, dry, or processed consumption. In addition, basil can be used as an ornamental or medicinal plant, increasing its appeal to indoor gardeners (Barbalho et al., 2012; Dou et al., 2018).

Recommended DLIs for commercial basil production range between 13 and $35 \mathrm{~mol} \cdot \mathrm{m}^{-2} \cdot \mathrm{d}^{-1}$ (Beaman et al., 2009; Dou et al., 2017; Moya et al., 2014; Somerville et al., 2014; Walters and Currey, 2018). However, when using cool-white fluorescent lamps in an indoor environment not designed for plant production, the recommended light intensity for human comfort and function

\begin{tabular}{llll}
\hline $\begin{array}{l}\text { Units } \\
\text { To convert U.S. to SI, } \\
\text { multiply by }\end{array}$ & U.S. unit & SI unit & $\begin{array}{l}\text { To convert SI to U.S., } \\
\text { multiply by }\end{array}$ \\
\hline 29.5735 & $\mathrm{fl} \mathrm{oz}$ & $\mathrm{mL}$ & 0.0338 \\
3.7854 & gal & $\mathrm{L}$ & 0.2642 \\
2.54 & inch(es $)$ & $\mathrm{cm}$ & 0.3937 \\
6.4516 & inch & $\mathrm{cm}^{2}$ & 0.1550 \\
0.0254 & $\mathrm{mil}(\mathrm{s})$ & $\mathrm{mm}$ & 39.3701 \\
1 & $\mathrm{mmho} / \mathrm{cm}$ & $\mathrm{dS} \cdot \mathrm{m}^{-1}$ & 1 \\
1 & $\mathrm{mmho} / \mathrm{cm}$ & $\mathrm{mS} \cdot \mathrm{cm}^{-1}$ & 1 \\
28.3495 & $\mathrm{oz}$ & $\mathrm{g}$ & 0.0353 \\
1 & $\mathrm{ppm}$ & $\mathrm{mg} \cdot \mathrm{L}^{-1}$ & 1 \\
$\left({ }^{\circ} \mathrm{F}-32\right) \div 1.8$ & ${ }^{\circ} \mathrm{F}$ & ${ }^{\circ} \mathrm{C}$ & $\left({ }^{\circ} \mathrm{C} \times 1.8\right)+32$
\end{tabular}


is $\approx 7 \mu \mathrm{mol} \cdot \mathrm{m}^{-1} \cdot \mathrm{s}^{-1}$, resulting in a DLI of $0.6 \mathrm{~mol} \cdot \mathrm{m}^{-2} \cdot \mathrm{d}^{-1}$ using a $24 \mathrm{~h} \cdot \mathrm{d}^{-1}$ photoperiod [adapted from U.S. General Services Administration (2013)]. Similarly, based on data we collected in multiple strategic locations within office, residential, and classroom environments, indoor light intensities using common electric lamps [e.g., fluorescent or light-emitting diode (LED) bulbs] can range from 5 to $1500 \mu \mathrm{mol} \cdot \mathrm{m}^{-2} \cdot \mathrm{s}^{-1}$, depending on the time of day and proximity to a lamp or sunlit location (e.g., window). These examples illustrate the need to supplement light for indoor food gardening of crops like basil, if grown in spaces that do not receive continuous direct sunlight.

Although studies have compared growth and quality responses of edible plants grown with sole-source lighting under different DLIs (Beaman et al., 2009; Dou et al., 2017, 2018; Ferreira Fernandes et al., 2013; He et al., 2001; Walters and Currey, 2018), most research has been conducted to address the needs of commercial growers who aim to maximize yield. Therefore, leafy greens for commercial production are typically grown with target DLIs in the range of 10 to $20 \mathrm{~mol} \cdot \mathrm{m}^{-2} \cdot \mathrm{d}^{-1}$, whereas $30 \mathrm{~mol} \cdot \mathrm{m}^{-2} \cdot \mathrm{d}^{-1}$ are commonly targeted when producing fruiting crops like tomato [Solanum lycopersicum (Beaman et al., 2009; Dorais et al., 2017; Kang et al., 2013)]. However, providing DLIs in those ranges is not likely to be a feasible strategy by indoor gardeners because 1) the recommended light intensity for human comfort results in less than $1 \mathrm{~mol} \cdot \mathrm{m}^{-2} \cdot \mathrm{d}^{-1}$ of light and 2) the cost for fixture installation and maintenance to provide sole-source lighting is not expected to result in an economic return and may limit the willingness of consumers to invest in lamps and electricity (Halleck, 2018; U.S. General Services Administration, 2013). Moreover, it is important to understand that most indoor gardeners are motivated by their desire to be actively involved in the growing and harvesting process and, thus, may be satisfied with having a reliable harvest for their personal use (Gao et al., 2009; Kortright and Wakefield, 2011). Therefore, DLIs that result in a constant supply of high-quality fresh produce, as opposed to those that maximize yield and profits, may be adequate to satisfy the motivation for indoor gardeners. Paz et al. (2019) recently showed that less than half the recommended DLI for commercial lettuce (Lactuca sativa) production is sufficient to maintain pick-and-eat plants with adequate nutritional qualities. Thus, through the use of DLIs below the recommended ranges for commercial production, one of our goals was to identify minimum DLIs that could sustain basil production for indoor gardeners.

\section{Changes in DLI over time}

Typically, the lighting strategy for commercial plant production indoors consists of adjusting the DLI during different plant stages, such as seedling, flowering, fruiting, or finish (Currey et al., 2017). However, the duration of these stages and the DLI requirements are crop specific and not always reported in the literature. Limited research has been conducted that evaluates the effect of a DLI Inc. Studies with ornamental plugs have shown that providing a $\mathrm{DLI}_{\text {Inc }}$ can result in similar SDW and leaf number compared with providing a constantly high DLI (Lopez and Runkle, 2008; Oh et al., 2010). However, few studies report plant growth under changing DLIs for edible crop production. Brechner and Both (2013) suggested that to maximize hydroponic lettuce yield indoors, a seedling stage of 11 $\mathrm{d}$ requires $22 \mathrm{~mol} \cdot \mathrm{m}^{-2} \cdot \mathrm{d}^{-1}$ using a 24 $\mathrm{h} \cdot \mathrm{d}^{-1}$ photoperiod, whereas a finish stage of $24 \mathrm{~d}$ requires $17 \mathrm{~mol} \cdot \mathrm{m}^{-2} \cdot \mathrm{d}^{-1}$ using a $20 \mathrm{~h} \cdot \mathrm{d}^{-1}$ photoperiod. However, van Iersel (2017) proposed that tailoring the intensity of light according to crop-specific photosynthetic efficiency could prove to be more beneficial than providing a set photosynthetic photon flux $(P P F)$ at predefined developmental stages. The author described the use of dynamic lighting by controlling $P P F$ precisely with dimming in response to certain physiological parameters, ultimately providing an opportunity for energy savings when producing high-value crops indoors. Similarly, Poulet et al. (2014) found that increasing DLI systematically as lettuce plants grow and develop can help reduce energy costs associated with sole-source lighting. Both aforementioned studies suggest that manipulating the light environment during the crop cycle can help optimize energy efficiency and plant productivity using electric lamps. Therefore, another goal of this study was to evaluate the use of $\mathrm{DLI}_{\text {Inc }}$ to determine whether plants grown under limited DLIs during the initial stages of production could be as productive as those grown constantly under higher DLIs.

Based on our two goals, the objective of this study was to quantify and compare growth and photosynthetic capacity over time of two basil cultivars grown hydroponically under constant $(4,6,8$, or $10 \mathrm{~mol} \cdot \mathrm{m}^{-2} \cdot \mathrm{d}^{-1}$ ) or increasing (from 4 to $\left.10 \mathrm{~mol} \cdot \mathrm{m}^{-2} \cdot \mathrm{d}^{-1}\right)$ DLIs. We hypothesized that basil plants grown under $\mathrm{DLI}_{\text {Inc }}$ would have a similar yield compared with those grown under a constant DLI of $10 \mathrm{~mol} \cdot \mathrm{m}^{-2} \cdot \mathrm{d}^{-1}$. We further hypothesized that plants produced under lower DLIs (4 or $6 \mathrm{~mol} \cdot \mathrm{m}^{-2} \cdot \mathrm{d}^{-1}$ ) would make more efficient use of the available light than those grown under higher DLIs $\left(8\right.$ or $\left.10 \mathrm{~mol} \cdot \mathrm{m}^{-2} \cdot \mathrm{d}^{-1}\right)$, for which light-response curves were measured to determine the light saturation point of photosynthesis and $A_{\max }$, as two potential indicators of the photosynthetic capacity of leaves.

\section{Materials and methods}

Plant Material AND growing CONDITIONs. Seeds of green 'Genovese Compact' and purple 'Red Rubin' basil (Johnny's Selected Seeds, Winslow, ME) were sown into 98-plug sheets (individual cell volume, $55 \mathrm{~mL}$ ) of rockwool (A-Ok starter plugs; Grodan, Roermond, The Netherlands) and germinated inside a walk-in growth chamber (C6 Control System with EcoSys Software; Environmental Growth Chambers, Chagrin Falls, $\mathrm{OH}$ ) at $21{ }^{\circ} \mathrm{C}, 400 \mathrm{ppm}$ of $\mathrm{CO}_{2}$, and $70 \%$ relative humidity $(\mathrm{RH})$. Until germination occurred, plants were irrigated as needed with tap water that had an electrical conductivity (EC) of $0.4 \mathrm{mS} \cdot \mathrm{cm}^{-1}$, a $\mathrm{pH}$ of 8.3 , and $40 \mathrm{mg} \cdot \mathrm{L}^{-1}$ calcium carbonate alkalinity.

At $15 \mathrm{~d}$ after sowing, uniform seedlings were selected and the experiment was initiated. Four seedlings were transplanted into a single deepwater culture hydroponic system using 2 -inch-diameter net cups. Each 2 -gal hydroponic system $(23 \mathrm{~cm}$ wide $\times$ $23 \mathrm{~cm}$ long $\times 19 \mathrm{~cm}$ tall) was rust colored and had a white plastic lid with four openings $(20 \mathrm{~cm}$ apart $)$ that 
held one net cup each. A clear plastic tube attached to an air pump (320 GPH, Dual Diaphragm Air Pump; General Hydroponics, Santa Rosa, CA) provided continuous aeration. Bamboo stakes $(40 \mathrm{~cm}$ tall) were used to provide physical support for the plants, which were secured as needed with twist ties. Plants were grown for 8 weeks inside two walk-in growth chambers (C6 Control System), each equipped with two opposite shelving units with two experimental compartments $(61 \mathrm{~cm}$ wide $\times 183 \mathrm{~cm}$ long $\times$ $94 \mathrm{~cm}$ tall). Each compartment had a unique lamp setup to create different light intensities. For each constant DLI treatment, four hydroponic systems (two per cultivar) were maintained permanently within each compartment. For the $\mathrm{DLI}_{\text {Inc }}$ treatment, four systems (two per cultivar) were moved to different compartments every 2 weeks (as described under "Treatments"). Within each chamber, constant ambient temperature, $\mathrm{CO}_{2}$ concentration, and $\mathrm{RH}$ were set at $21{ }^{\circ} \mathrm{C}, 400 \mathrm{ppm}$, and $70 \%$, respectively.

Treatments. The light treatments consisted of four target DLIs: $4\left(\mathrm{DLI}_{4}\right), 6\left(\mathrm{DLI}_{6}\right), 8\left(\mathrm{DLI}_{8}\right)$, and 10 $\left(\mathrm{DLI}_{10}\right) \mathrm{mol} \cdot \mathrm{m}^{-2} \cdot \mathrm{d}^{-1}$, which were achieved by using PPFs of 80,119 , 159 , and $197 \pm 5 \mu \mathrm{mol} \cdot \mathrm{m}^{-2} \cdot \mathrm{s}^{-1}$, respectively, and a constant $14 \mathrm{~h} \cdot \mathrm{d}^{-1}$ photoperiod (0600 to $2000 \mathrm{HR}$ ). DLI Inc $_{\text {Inc }}$ used as a fifth treatment, which was achieved by moving two hydroponic systems per cultivar systematically to a treatment with a greater DLI every 2 weeks (starting with $\mathrm{DLI}_{4}$ and ending with $\mathrm{DLI}_{10}$ ). A light map was generated before treatment initiation to determine the maximum $P P F$ at mid-canopy height using a spectroradiometer (SS-110; Apogee Instruments, Logan, UT). The target PPFs were provided by broad-spectrum LED lamps, where 93\% of the PPF was delivered by lamps with a fixed output (GreenPower; Signify United States, Somerset, NJ) and $7 \%$ by lamps with dimmable settings (RAY66 lamps; Fluence Bioengineering, Austin, TX). The light output to achieve a target $P P F$ and a uniform spectral distribution was controlled by adjusting the number of lamps and/or the dimmer settings (Fig. 1). Light pollution $(<5$ $\left.\mu \mathrm{mol} \cdot \mathrm{m}^{-2} \cdot \mathrm{s}^{-1}\right)$ within treatments was minimized by covering the sides and

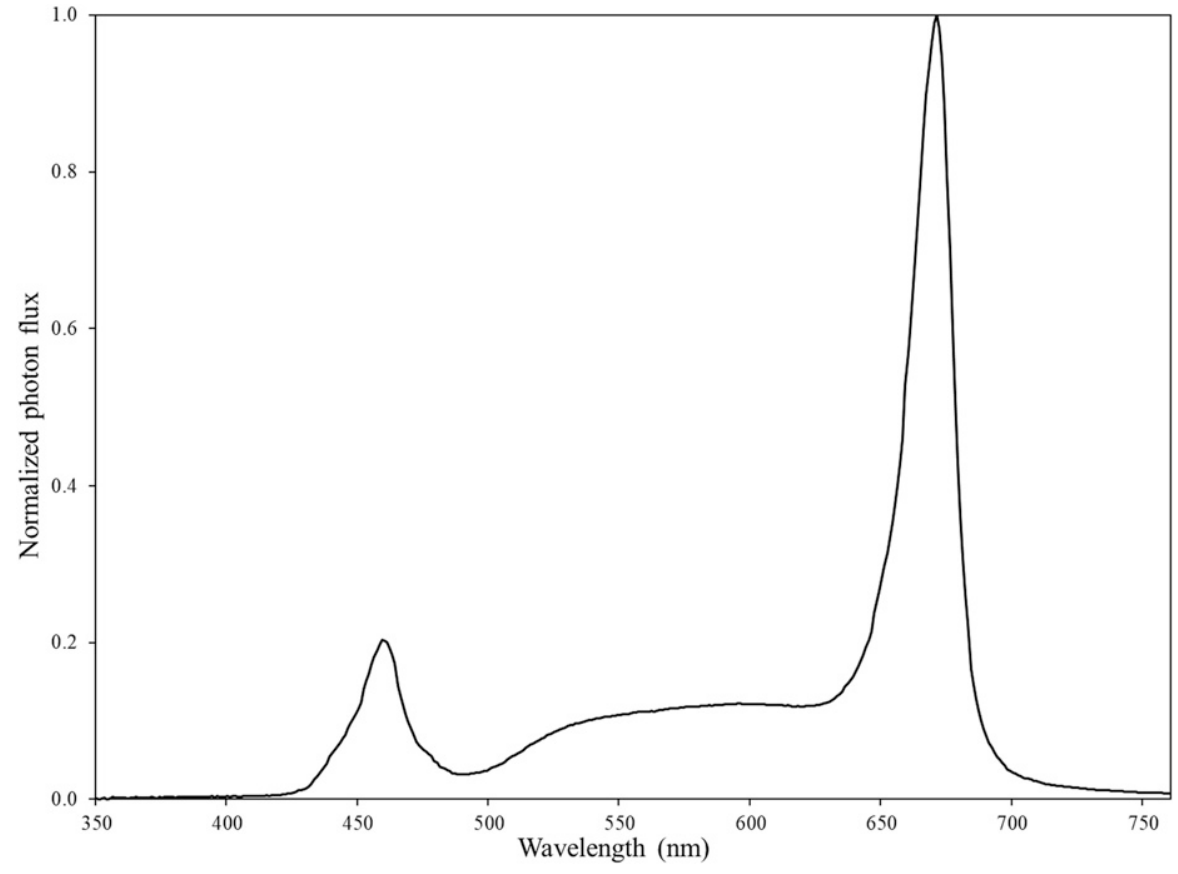

Fig. 1. Normalized spectral power distribution of the lamps used in the experiment. Photon flux $\left(\mu \mathrm{mol} \cdot \mathrm{m}^{-2} \cdot \mathrm{s}^{-1}\right)$ was measured for every $1 \mathrm{~nm}$.

back of the shelves with a double layer of 6-mil-thick black and white polyethylene film (white side facing the plants). A black and white polyethylene film curtain $(215 \mathrm{~cm}$ long $\times 200$ $\mathrm{cm}$ tall) was used to prevent light pollution between the two opposite shelves (black side facing the plants). The curtain was placed in the middle of each chamber, $30 \mathrm{~cm}$ apart from the shelves to allow for sufficient air circulation. In addition, a foam board was placed at the bottom of each compartment to provide insulation from the metallic shelves. All hydroponic systems within each treatment were rotated randomly daily to minimize location effects within the experimental area.

Plants had a complete nutrient solution replacement 4 weeks after treatment initiation. The nutrient solution consisted of a two-part liquid fertilizer mix with different nitrogen $(\mathrm{N})$, phosphorous $(\mathrm{P})$, and potassium (K) quantities. Plants within one system were fertilized with $20 \mathrm{~mL} 4 \mathrm{~N}-$ $0 \mathrm{P}-0.8 \mathrm{~K}$ and $20 \mathrm{~mL} 2 \mathrm{~N}-1.3 \mathrm{P}-5.8 \mathrm{~K}$ (Root Farm Nutrients; Hawthorne Gardening Co., Marysville, $\mathrm{OH}$ ) to obtain a concentration of $231 \mathrm{mg} \cdot \mathrm{L}^{-1}$ $\mathrm{N}$. EC and $\mathrm{pH}$ of the nutrient solution were monitored weekly with an $\mathrm{EC}$ and $\mathrm{pH}$ meter (HI 9813-6N waterproof; Hanna Instruments, Carrollton, TX) to ensure that values were maintained within recommended ranges for basil $\left(1.0-1.6 \mathrm{dS} \cdot \mathrm{m}^{-1}\right.$ EC and 5.5-6.5 pH) (Moya et al., 2014; Somerville et al., 2014). Nearcanopy air temperature was measured with one type- $\mathrm{K}$ thermocouple (diameter, $0.1 \mathrm{~mm}$ ) placed in the middle of every compartment underneath a leaf located at mid-canopy height. Thermocouples were interfaced to a multiplexer (AMl6/32B; Campbell Scientific, Logan, UT) and data were recorded with a data logger at 10-min intervals (CRI000; Campbell Scientific). The mean \pm SD of nearcanopy air temperate values recorded throughout the experiment and averaged across replications were $20.8 \pm$ $1.2,21.1 \pm 1.1,21.3 \pm 1.1$, and $21.5 \pm$ $1.3{ }^{\circ} \mathrm{C}$ for $\mathrm{DLI}_{4}, \mathrm{DLI}_{6}, \mathrm{DLI}_{8}$, and $\mathrm{DLI}_{10}$, respectively.

Data collected. Photosynthetic light-response curves were measured before destructive harvests at weeks 4,6 , and 8 after treatment initiation. Because leaves were too small $\left(<6 \mathrm{~cm}^{2}\right)$ to measure at week 2 , light-response curve data were not collected. Measurements were made on one plant per system per treatment. Data were collected using a portable photosynthesis system (LI-6400xt; LI-COR Biosciences, Lincoln, NE) under six different PPFs $(600,400,200,100,75$, and $\left.0 \mu \mathrm{mol} \cdot \mathrm{m}^{-2} \cdot \mathrm{s}^{-1}\right)$. The reference $\mathrm{CO}_{2}$ 
concentration, leaf temperature, and flow rate inside the chamber were $400 \pm 5 \mu \mathrm{mol} \cdot \mathrm{mol}^{-1}, 21^{\circ} \mathrm{C}$, and 500 $\mathrm{mL} \cdot \mathrm{min}^{-1}$, respectively. Data were fitted to the following model equation (Jurik et al., 1988):

$$
\begin{aligned}
& A_{\text {net }}=-R d \\
& +\frac{\theta \times P P F+A_{\max }-\sqrt{ }\left(\theta \times P P F+A_{\max }\right)_{2}-4 \theta \times P P F \times k \times A_{\max }}{2 k}
\end{aligned}
$$

where $A_{\text {net }}$ is the net $\mathrm{CO}_{2}$ assimilation rate, $R d$ is dark respiration, $\theta$ is the quantum use efficiency, $P P F$ is the incident irradiance, $A_{\max }$ is the maximum gross $\mathrm{CO}_{2}$ assimilation (lightsaturated net $\mathrm{CO}_{2}$ assimilation $+R d$ ), and $k$ is the curvature factor describing the convexity of the curve (range, 0-1). The light compensation point and light saturation point were calculated as the $P P F$-associated photosynthetic rates when $A_{\text {net }}=0$ and $A_{\text {net }}=$ $A_{\max } \times 0.90$, respectively (Jurik et al., 1988).

For each cultivar, one plant per system per treatment was harvested destructively every 2 weeks. Shoots were cut at the base of the stem near the substrate plug. The number of leaves $(>1 \mathrm{~cm})$ per plant was counted and total leaf area was measured using a leaf area meter (LI-3100C, LI-COR Biosciences). Shoots (stem and leaves) and roots were weighed separately with an electronic balance to obtain SFW and root fresh weight (RFW), respectively. Tissue was oven-dried at $70{ }^{\circ} \mathrm{C}$ for $72 \mathrm{~h}$ to determine SDW and root dry weight (RDW), respectively.

Data analysis. Within each chamber, data from the two hydroponic systems per cultivar per treatment were pooled and averaged to be used as a single data point. Each treatment $\times$ cultivar combination was replicated two times in space (once within each growth chamber) and twice over time. All lighting treatments were rerandomized within each chamber before the start of the second replication over time. In our statistical model, random effects were experimental replication and its interaction with treatment and cultivar. The treatment $\times$ cultivar interaction was not significant $(P>0.05)$; thus, pairwise comparisons for the main effect treatment means were used for the analyses $(n=8)$. A regression analysis was conducted to compare growth trends measured for plants grown under all constant DLI treatments $\left(\mathrm{DLI}_{4}, \mathrm{DLI}_{6}, \mathrm{DLI}_{8}\right.$, and $\mathrm{DLI}_{10}$ ) using SigmaPlot (version 13.0; Systat Software, San Jose, CA). For each response variable, we evaluated both a linear and a quadratic fit; a linear fit was chosen as the appropriate model based on the $r^{2}$ value. A nonrectangular hyperbola was used to fit the light-response curve data using the nonlinear fitting procedure of SAS (version 9.4; SAS Institute, Cary, NC). However, because we were unable to measure light-response curves at week 2 and thus, only three data points were available, we chose not to use a regression analysis. Growth and light-response curve data comparing $\mathrm{DLI}_{\text {Inc }}$ to all other treatments were analyzed using a Dunnett test with JMP (version 12, SAS Institute). Graphs for week 2 are not shown in Fig. 2 because data points were orders of magnitude less than those at weeks 4,6 , and 8 . However, where appropriate, trends for week 2 are described throughout the Results section.

\section{Results}

Growth Responses. Except for leaf number at week 2 and RDW at week 4, all growth variables increased linearly in response to $\mathrm{DLI}_{\text {Inc }}$ (Fig. 2). There were no significant differences in leaf number between DLI Inc $_{\text {Ind all other treatments at }}$ week 2 (data not shown). However, $\mathrm{DLI}_{8}$ and $\mathrm{DLI}_{10}$ had $71 \%, 48 \%$, and $36 \%$; and $107 \%, 116 \%$, and $163 \%$ more leaves than $\mathrm{DLI}_{\text {Inc }}$ at weeks 4 , 6 , and 8 , respectively. In addition, $\mathrm{DLI}_{6}$ produced significantly more leaves than $\mathrm{DLI}_{\text {Inc }}$ at week 4 , and plants grown under $\mathrm{DLI}_{10}$ had $156 \%, 140 \%$, and 198\% larger leaves than $\mathrm{DLI}_{\text {Inc }}$ at weeks 2, 4, and 6, respectively. Leaf area was significantly smaller for plants grown under $\mathrm{DLI}_{\text {Inc }}$ compared to those grown under $\mathrm{DLI}_{8}$ and $\mathrm{DLI}_{10}$ at week 2 . However, at week 8 , leaf area was similar among $\mathrm{DLI}_{6}, \mathrm{DLI}_{8}, \mathrm{DLI}_{10}$, and $\mathrm{DLI}_{\text {Inc. In addition, }} \mathrm{DLI}_{\text {Inc }}$ produced $73 \%$ larger leaves than $\mathrm{DLI}_{4}$ at week 8 .

Except for week 2, responses for SFW and SDW showed similar trends across weeks (Fig. 2). We found that, in general, $\mathrm{DLI}_{10}$ produced significantly more SFW and SDW than $\mathrm{DLI}_{\text {Inc }}$, with percentage increases ranging from $40 \%$ to $181 \%$ and $45 \%$ to $227 \%$, respectively. Similarly, except for SDW at week 2, plants grown under $\mathrm{DLI}_{8}$ were generally larger than those grown under $\mathrm{DLI}_{\mathrm{Inc}}$ at weeks 2, 4, and 6. Nonetheless, $\mathrm{DLI}_{4}$ produced $62 \%$ and $53 \%$ less SFW and SDW, respectively, compared with $\mathrm{DLI}_{\text {Inc }}$ at week 8 . No significant differences were measured for RDW between $\mathrm{DLI}_{\mathrm{Inc}}$ and all other treatments at weeks 2, 4, and 8 . However, $\mathrm{DLI}_{10}$ produced almost three times the RDW than $\mathrm{DLI}_{\text {Inc }}$ at week 6.

Physiological responses. Except for week 8 , no treatment differences were measured for dark respiration, $A_{\max }$, and the light compensation point (Table 1). At week 8 , dark respiration for plants grown under $\mathrm{DLI}_{8}$ and $\mathrm{DLI}_{10}$ was up to $56 \%$ and $78 \%$ greater than that for plants grown under $\mathrm{DLI}_{4}$ and $\mathrm{DLI}_{6}$, respectively. Also at week 8 , plants grown under $\mathrm{DLI}_{8}, \mathrm{DLI}_{10}$, and $\mathrm{DLI}_{\text {Inc }}$ had $25 \%, 20 \%$, and $15 \%$, respectively, greater $A_{\max }$ values compared to those grown under $\mathrm{DLI}_{4}$. In addition, at week 8, the light compensation point for plants grown under $\mathrm{DLI}_{8}, \mathrm{DLI}_{10}$, and DLI Inc was significantly greater than that measured for plants grown under $\mathrm{DLI}_{4}$, ranging from 21.5 to $24.4 \mu \mathrm{mol} \cdot \mathrm{m}^{-2} \cdot \mathrm{s}^{-1}$. No treatment differences were measured for the light saturation point across weeks.

\section{Discussion}

Young plants with small leaves are not expected to have the same capacity for photosynthesis as mature plants with larger leaves that can capture radiation more efficiently (Nobel et al., 1975). Therefore, guidelines typically recommend lower DLIs to be used during propagation compared with production (Brechner and Both, 2013; Currey et al., 2017; Poulet et al., 2014). Based on this general recommendation, one of our goals was to measure growth and development over time to evaluate the effects of $\mathrm{DLI}_{\text {Inc }}$ throughout the 8-week production cycle.

Our data indicate that by providing a $\mathrm{DLI}_{\text {Inc }}$, basil plants were ultimately as productive as those grown under $\mathrm{DLI}_{8}$, with overall SFW and SDW ranging from 120 to $151 \mathrm{~g}$ and 10 to $12 \mathrm{~g}$, respectively (Fig. 2). However, values for SFW and SDW of plants grown under 

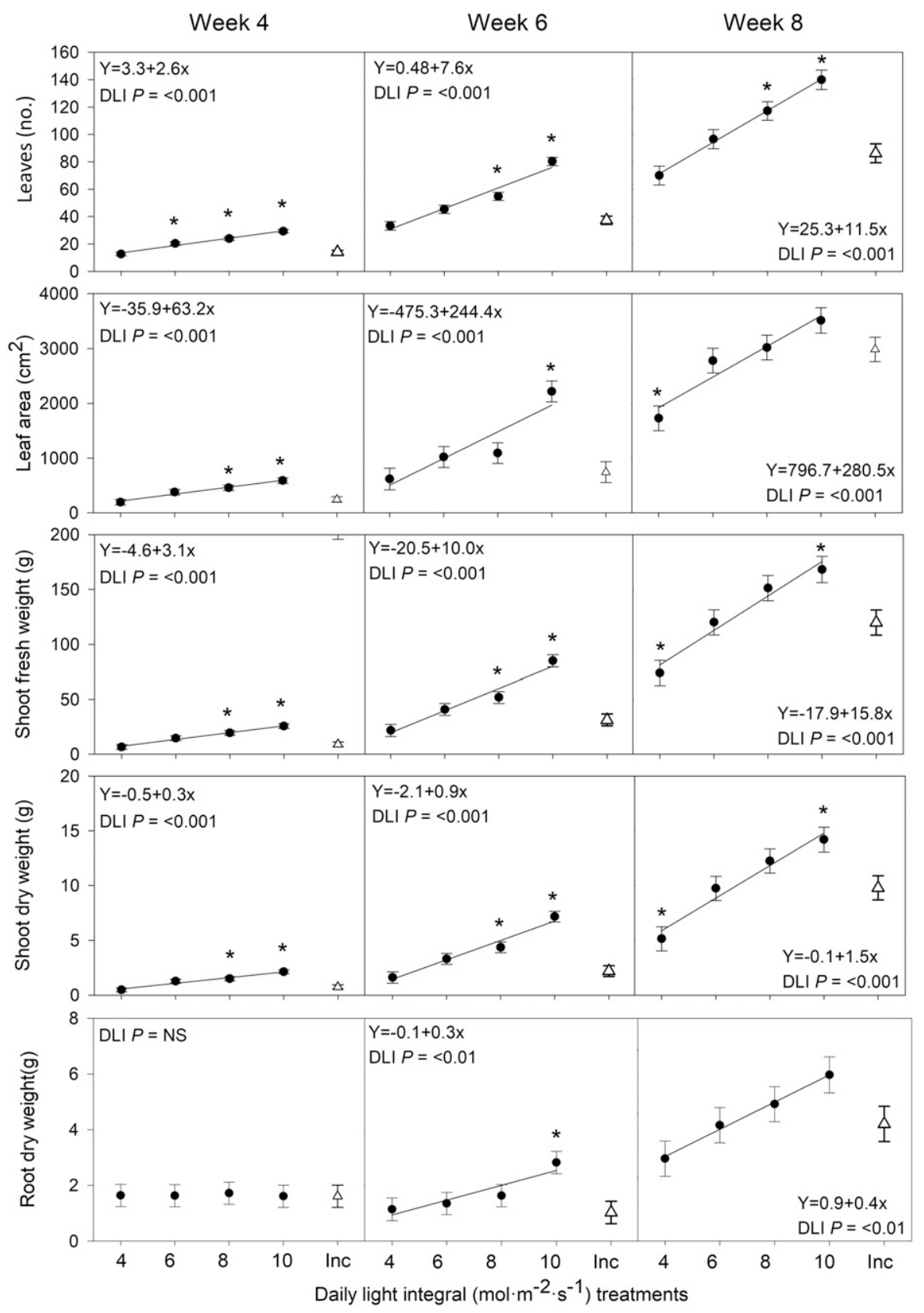

Fig. 2. Effect of daily light integral (DLI) on growth parameters for basil at different harvest dates. Plants were grown under one of four constant DLI treatments: $4,6,8$, or $10 \mathrm{~mol} \cdot \mathrm{m}^{-2} \cdot \mathrm{d}^{-1}$, or an increasing DLI (Inc) (from 4 to 10 $\mathrm{mol} \cdot \mathrm{m}^{-2} \cdot \mathrm{d}^{-1}$, increased every 2 weeks $)$. Black circles represent the mean \pm SE of four replications and two cultivars: Genovese Compact and Red Rubin $(n=8)$.

Asterisks (*) depict significant differences between Inc (white triangle) and all other treatments according to the Dunnett test $(P \leq 0.05) ; 1 \mathrm{~cm}^{2}=0.1550 \mathrm{inch}^{2}$, $1 \mathrm{~g}=0.0353 \mathrm{oz}$.

$\mathrm{DLI}_{\text {Inc }}$ were consistently less than those of plants grown under $\mathrm{DLI}_{10}$, even if at week 8 , leaf area was similar between both treatments. Surprisingly, across weeks, plants grown under $\mathrm{DLI}_{8}$ and $\mathrm{DLI}_{10}$ had significantly fewer leaves than those grown under DLI $_{\text {Inc. In addition, although not }}$ measured in our study, leaves of plants grown under $\mathrm{DLI}_{\text {Inc }}$ were visibly thinner than those grown under $\mathrm{DLI}_{10}$. In agreement with our observation, leaves that develop under light-limited environments tend to be irreversibly thin, which is an acclimation response that maximizes radiation captured across the leaf surface (Castro-Díez et al., 2000; Oguchi et al., 2003; Peralta et al., 2002; Sims and Pearcy, 1992; Yamashita et al., $2000)$. Considering that shoot biomass production is, in general, directly proportional to leaf area, leaf thickness, and sometimes leaf number (Aranda et al., 2004), the DLI effect on leaf number and leaf thickness is most likely responsible for the biomass responses measured in our study.

Although it is likely that toward the end of the experiment, newly developed leaves of plants grown under DLI Inc had similar traits (e.g., leaf area and thickness) as those grown under constantly greater DLIs, the limited DLI provided during the initial growth stages affected the overall growth capacity of plants grown under DLI Inc (Fig. 2). Frak et al. (2001) showed that mature leaves developed under light-limited environments are able to adjust their photosynthetic capacity when exposed to high PPF values. Nonetheless, developmental limitations in response to low-light environments, such as leaf thickness, chloroplast abundance, and chlorophyll content, ultimately drive the capacity of plants to photosynthesize and produce biomass (Terfa et al., 2013). Therefore, in our study, providing constantly high DLIs was more beneficial than increasing the DLI over time, because it enabled plants to produce ultimately more biomass.

The regression analysis indicates that, in general, as DLI increased, growth increased linearly (Fig. 2). Across weeks, plants grown under $\mathrm{DLI}_{8}$ and $\mathrm{DLI}_{10}$ consistently produced more and larger leaves than those grown under lower DLIs $(<6$ $\left.\mathrm{mol} \cdot \mathrm{m}^{-2} \cdot \mathrm{d}^{-1}\right)$. Similar to our results, Ferreira Fernandes et al. (2013) reported linear or quadratic increases in the number of inflorescences, leaves, and RDW of basil plants when comparing growth under 10 vs. $20 \mathrm{~mol}$ $\mathrm{m}^{-2} \cdot \mathrm{d}^{-1}$. Walters and Currey (2018) also found that edible yield of basil can increase linearly, with DLIs ranging from $\approx 7$ to $19 \mathrm{~mol} \cdot \mathrm{m}^{-2} \cdot \mathrm{d}^{-1}$. However, Chang et al. (2008) reported no differences in biomass production for basil plants grown in a greenhouse under 13 or $25 \mathrm{~mol} \cdot \mathrm{m}^{-2} \cdot \mathrm{d}^{-1}$, but SFM, SDM, and leaf area were lowest under a DLI of $5 \mathrm{~mol} \cdot \mathrm{m}^{-2} \cdot \mathrm{d}^{-1}$. Similarly, Beaman et al. (2009) showed that basil grown under DLIs from 17 to $23 \mathrm{~mol} \cdot \mathrm{m}^{-2} \cdot \mathrm{d}^{-1}$ had no differences in plant height, canopy diameter, 
Table 1. Photosynthetic parameters estimated from light-response curves measured at week (W) 4, 6, and 8 for basil plants grown in a growth chamber under one of five lighting treatments.

\begin{tabular}{|c|c|c|c|c|c|c|c|c|c|c|c|c|}
\hline \multirow{3}{*}{$\begin{array}{l}\text { DLI treatment } \\
\left(\mathrm{mol} \cdot \mathrm{m}^{-2} \cdot \mathrm{d}^{-1}\right)^{\mathrm{z}}\end{array}$} & \multicolumn{3}{|c|}{ Dark respiration } & \multicolumn{3}{|c|}{$\begin{array}{l}\text { Maximum gross } \\
\mathrm{CO}_{2} \text { assimilation }\end{array}$} & \multicolumn{3}{|c|}{$\begin{array}{c}\text { Light compensation } \\
\text { point }\end{array}$} & \multicolumn{3}{|c|}{ Light saturation point } \\
\hline & \multicolumn{12}{|c|}{$\left(\mu \mathrm{mol} \cdot \mathrm{m}^{-2} \cdot \mathrm{s}^{-1}\right)$} \\
\hline & W4 & W6 & W8 & W4 & W6 & W8 & W4 & W6 & W8 & W4 & W6 & W8 \\
\hline 4 & $0.8^{\mathrm{y}}$ & 0.9 & 0.9 & 9.6 & 10.6 & $11.9^{*}$ & 12.8 & 16.4 & $17.9^{*}$ & 392.4 & 415.9 & 468.7 \\
\hline 6 & 0.9 & 0.9 & 1.0 & 10.0 & 11.3 & 12.8 & 13.9 & 19.2 & 19.1 & 427.3 & 458.7 & 487.9 \\
\hline 8 & 1.0 & 0.9 & 1.4 & 10.9 & 11.9 & 14.9 & 15.6 & 21.7 & 23.2 & 459.2 & 497.2 & 545.1 \\
\hline
\end{tabular}

${ }^{\mathrm{z}}$ Four constant daily light integrals (DLIs): $4,6,8$, or $10 \mathrm{~mol} \cdot \mathrm{m}^{-2} \cdot \mathrm{d}^{-1}$ or an increasing DLI [DLI Inc $\left(\right.$ from 4 to $10 \mathrm{~mol} \cdot \mathrm{m}^{-2} \cdot \mathrm{d}^{-1}$, increased every $2 \mathrm{weeks}$ )].

${ }^{\mathrm{y}}$ Data represent the mean of four replications and two cultivars: Genovese Compact and Red Rubin $(\mathrm{n}=8)$. Means within a column marked with an asterisk ( $\left.{ }^{\star}\right)$ are different from DLI $\mathrm{Inc}_{\text {Inc }}$ based on the Dunnett test $(P \leq 0.05)$.

or yield. In our study, the PPFs used for the DLI treatments were significantly lower than those used by Beaman et al. (2009) and Chang et al. (2008). It is likely that the $P P F$ values used in the aforementioned studies approached the light saturation point, and thus further increases in DLI had no positive effects in growth. In contrast, our results indicate that the $P P F$ values used in our different DLI treatments were less than half the intensity that would saturate photosynthesis (Table 1 ), suggesting that growth and yield could increase further with greater $P P F$ values.

Our findings are in agreement with studies indicating that DLI increases growth and yield linearly for crops with high-harvest indexes, such as leafy greens and herbs (Chang et al., 2008; Walters and Currey, 2018). Nonetheless, our data describe basil growth under DLIs less than those typically used for commercial production (Fig. 2). Therefore, our results are not directly comparable with most of the literature, which tends to report significantly greater yields as a result of greater DLIs. For example, Dou et al. (2017) produced $23 \mathrm{~g}$ fresh weight per plant when 'Genovese Compact' basil plants were grown for 3 weeks under DLIs in the range of 12 to $18 \mathrm{~mol} \cdot \mathrm{m}^{-2} \cdot \mathrm{d}^{-1}$. Similarly, Majkowska-Gadomska et al. (2017) reported that 'Genovese' basil plants grown in northern Europe inside a greenhouse without supplemental lighting from April through May can yield up to $330 \mathrm{~g}$ fresh weight per plant. In addition, Omobolanle Ade-Ademilua et al. (2013) reported that clove basil (Ocimum gratissimum) grown under full sunlight can yield $38 \mathrm{~g}$ fresh weight per plant, which is almost double the yield of plants grown under 50\% shade $(20 \mathrm{~g}$; duration of treatment not reported). Results from these studies indicate that greater DLIs can increase growth and yield of basil significantly, which is in agreement with our findings. However, our data are reflective of the limited DLI ranges used in our study.

In a study that compared two DLI treatments $\left(7\right.$ vs. $15 \mathrm{~mol} \cdot \mathrm{m}^{-2} \cdot \mathrm{d}^{-1}$ ), Walters and Currey (2018) reported that 'Red Rubin' basil grown under 7 $\mathrm{mol} \cdot \mathrm{m}^{-2} \cdot \mathrm{d}^{-1}$ produced $\approx 143$ and $9 \mathrm{~g}$ SFW and SDW, respectively, during a 4-week production cycle. Nonetheless, to our knowledge, no other studies have reported data that would support growth and yield of basil plants grown under DLIs less than those typically used for commercial production $\left(<10 \mathrm{~mol} \cdot \mathrm{m}^{-2}\right.$. $\mathrm{d}^{-1}$ ). Thus, considering human comfort and limitations within spaces not designed for plant production purposes, our findings are relevant to consumers interested in producing edible crops for indoor gardening. In view that consumers typically purchase commercial packages of fresh sweet basil containing 20 to $55 \mathrm{~g}$ on average (based on locally available products), the SFW of plants produced under $\mathrm{DLI}_{\text {Inc }}, \mathrm{DLI}_{8}$, and $\mathrm{DLI}_{10}$, which ranged from 120 to $168 \mathrm{~g}$, could satisfy the needs of indoor gardeners who are likely to grow basil for pick-and-eat purposes. Furthermore, gradually increasing the DLI, as opposed to using a constant DLI of $8 \mathrm{~mol} \cdot \mathrm{m}^{-2} \cdot \mathrm{d}^{-1}$, might help reduce the energy costs associated with the use of electric lamps for indoor gardening (Poulet et al., 2014). However, this strategy could be considered time-consuming or burdensome, because it may increase the effort of growing basil for indoor gardening.

Although not measured in our study, we observed that plants grown under $\mathrm{DLI}_{10}$ produced more inflorescences than those grown under lower DLIs $\left(<8 \mathrm{~mol} \cdot \mathrm{m}^{-2} \cdot \mathrm{d}^{-1}\right)$. This is similar to what Ferreira Fernandes et al. (2013) reported, in that basil grown under $4,7,11$, and $20 \mathrm{~mol} \cdot \mathrm{m}^{-2} \cdot \mathrm{d}^{-1}$ had an inflorescence dry weight of $\approx 0.5,2.2,9.3$, and $14.7 \mathrm{~g}$, respectively. Moccaldi and Runkle (2007) showed that by reducing $P P F$ values, growers can delay flowering and extend the vegetative stage of Salvia splendens and Tagetes patula. Flowering of basil plants can accelerate the decline in quality attributes by inducing bitterness and reducing aroma (Barbalho et al., 2012; Raimondi et al., 2006). Considering that indoor gardeners tend to grow basil for edible purposes, lower DLIs might help prolong the vegetative stage of basil plants while maintaining visual appeal, which was considered acceptable across all treatments evaluated in our study (e.g., no chlorotic or etiolated tissue and adequate plant firmness).

Although the photosynthetic capacity of a single leaf cannot be extrapolated to our growth data, light-response curves were measured to help elucidate whether leaves developed under constantly high DLIs had a greater photosynthetic capacity compared to those grown under DLI Inc $_{\text {I Table 1). In addition, calcu- }}$ lated values from light-response curves helped determine the minimum light requirement to grow basil for indoor gardening. According to McDonald (2003), leaves developed under high light tend to have greater metabolic requirements than those 
developed under low light. Therefore, to sustain the photosynthetic demand from high organelle activity, leaves acclimated to greater $P P F$ values have greater dark respiration than those acclimated to lower PPF values (McDonald, 2003). Accordingly, our results show that at week 8, dark respiration for $\mathrm{DLI}_{8}$ and $\mathrm{DLI}_{10}$ was up to $40 \%$ and $78 \%$ greater than that of plants grown under $\mathrm{DLI}_{4}$ and $\mathrm{DLI}_{6}$, respectively (Table 1). Our findings are similar to those of Nemali and van Iersel (2004), who found a significant increase in dark respiration of wax begonia (Begonia semperflorens-cultorum) with greater DLIs. They suggested that a decrease in dark respiration in response to low DLI is an acclimation response that increases the net carbon gain of plants grown under limited light (Nemali and van Iersel, 2004).

As indicated by $A_{\max }$, the photosynthetic capacity of plants was similar across treatments during weeks 4 and 6 (Table 1). Because no significant differences were measured at the leaf level for $A_{\max }$ throughout production, we can infer that morphological and developmental traits (e.g., leaf thickness, leaf number, and leaf area) regulated by DLI during the initial production stages are most likely responsible for the growth responses measured in our study. Thus, $A_{\max }$ is not a good indicator for the capacity of whole plants to make use of the available light for photosynthesis (Fig. 2). Nonetheless, our results show that at week 8 , plants grown under $\mathrm{DLI}_{8}, \mathrm{DLI}_{10}$, and $\mathrm{DLI}_{\text {Inc }}$ had $15 \%$ to $25 \%$ greater $A_{\max }$ than those grown under $\mathrm{DLI}_{4}$. Similar to our findings, Oguchi et al. (2003) reported that if herbs are transferred from low $\left(70 \mu \mathrm{mol} \cdot \mathrm{m}^{-2} \cdot \mathrm{s}^{-1}\right)$ to high $\left(700 \mu \mathrm{mol} \cdot \mathrm{m}^{-2} \cdot \mathrm{s}^{-1}\right)$ PPF values, $A_{\max }$ increases; however, values are not comparable to those from leaves developed under high $P P F$ values. In addition, although new growth may adapt to greater $P P F$ values, leaf thickness and leaf area of preexisting leaves do not change (Oguchi et al., 2003). Therefore, increases in photosynthetic capacity for leaves of plants transferred from a low to high $P P F$ do not necessarily contribute to more growth, because increases in overall photosynthetic capacity of whole plants may be limited by anatomical, morphological, and physiological characteristics of preexisting leaves (Baille et al., 1996; Fan et al., 2013; Sims and Pearcy, 1992).

Typically, values for the light compensation point and the light saturation point for plants grown under high light intensities are greater than those for plants grown under low light intensities, indicating that when grown under low $P P F$ values, plants have a limited capacity to process absorbed light into photosynthetic products (Gu et al., 2008). Therefore, it was not surprising that the light compensation point at week 8 was the lowest for leaves developed under $\mathrm{DLI}_{4}$ (Table 1). Although we found that the light saturation point was unaffected by DLI, the general trends indicate an increase in the light saturation point with greater DLIs, suggesting that as plants mature, their capacity to use light for photosynthesis increases. This corresponds with the findings of Nemali and van Iersel (2004), who showed that both the light compensation and light saturation points of wax begonia increased with greater DLIs, but the increases were not statistically significant. Similar to our results, Park et al. (2016) found that the light saturation point for basil grown under $200 \mu \mathrm{mol} \cdot \mathrm{m}^{-2} \cdot \mathrm{s}^{-1}$ is $\approx 500 \mu \mathrm{mol} \cdot \mathrm{m}^{-2} \cdot \mathrm{s}^{-1}$. Photosynthesis at $P P F$ values beyond the light saturation point is typically limited by $\mathrm{CO}_{2}$ concentration, metabolism of triose phosphates, and/or rubisco activity, all of which can limit the efficiency of plants to use light (Ehleringer and Sandquist, 2010; von Caemmerer and Farquhar, 1981). This is in agreement with studies indicating that, although growth and yield continue to increase with DLI, light use efficiency is greater when plants are grown under lower DLIs (He et al., 2001; van Iersel, 2017). Accordingly, van Iersel (2017) showed that dynamic lighting (i.e., lighting adapted to crop-specific photosynthetic capacity) can help optimize energy use efficiency and plant productivity when plants are grown indoors with electric lamps. Low values for the light compensation point and the light saturation point could be beneficial for indoor gardening, because the $P P F$ values required to promote photosynthesis could be provided by electric lamps at levels that are comfortable for the human eye (Halleck, 2018).
In conclusion, considering the differences in growth and development across weeks, providing a constantly high DLI is more beneficial for basil grown for indoor gardening than increasing the DLI over time because it increases yield. Because, in general, the light saturation point and $A_{\max }$ were unaffected by DLI throughout most of the production cycle, the capacity of individual leaves to photosynthesize is not a good indicator of the capacity of whole plants to make use of the available light for photosynthesis and growth. Instead, developmental and morphological traits regulated by DLI during the initial stages of production are most likely responsible for the biomass responses measured in our study.

Addressing the needs of the emerging indoor food gardening movement, we have begun to characterize the minimum light requirements to grow basil plants indoors. To ensure a positive experience for indoor gardeners, further work is needed to identify minimum DLI requirements for other crops, keeping in mind that fruiting crops may require significantly greater DLIs than leafy greens and culinary herbs. In addition, market studies would help elucidate consumer preferences for acceptable yield and quality, as well as knowledge gaps that limit a successful indoor food gardening experience. Well-established recommendations for commercial food production in controlled environments may not be appropriate or relevant for smallscale, noncommercial indoor gardeners. Instead, new approaches and strategies should be developed to help expand niche market opportunities for indoor plant production.

\section{Literature cited}

Aranda, I., F. Pardo, L. Gil, and J.A. Pardos. 2004. Anatomical basis of the change in leaf mass per area and nitrogen investment with relative irradiance within the canopy of eight temperate tree species. Acta Oecol. 25:187-195.

Baille, M., R. Romerio-Aranda, and A. Baille. 1996. Gas-exchange responses of rose plants to $\mathrm{CO}_{2}$ enrichment and light. J. Hort. Sci. 71:945-956.

Barbalho, S.M., F.M. Vasques Farinazzi Machado, J.D.S. Rodrigues, T.H. Pereira Da Silva, and R. De Alvares Goulart. 2012. Sweet basil (Ocimum basilicum): 
Much more than a condiment. TANG Humanitas Medicine 2:1-5.

Beaman, A., R.J. Gladon, and J.A. Schrader. 2009. Sweet basil requires an irradiance of $500 \mu \mathrm{mol} \cdot \mathrm{m}^{-2} \cdot \mathrm{s}^{-1}$ for greatest edible biomass production. HortScience 44:64-67.

Brechner, M. and A.J. Both. 2013. Hydroponic lettuce handbook. Cornell University, Ithaca, NY.

Castro-Díez, P., J.P. Puyravaud, and J.H.C. Cornelissen. 2000. Leaf structure and anatomy as related to leaf mass per area variation in seedlings of a wide range of woody plant species and types. Oecologia 124:476-486.

Chang, X., P.G. Alderson, and C.J. Wright. 2008. Solar irradiance level alters the growth of basil (Ocimum basilicum L.) and its content of volatile oils. J. Environ. Expt. Bot. 63:216-223.

Currey, C.J., D.A. Kopsell, N.S. Mattson, J.K. Craver, R.G. Lopez, J.E. Erwin, and C. Kubota. 2017. Supplemental and solesource lighting of leafy greens, herbs, and microgreens, p. 170-175. In: R. Lopez and E. Runkle (eds.). Light management in controlled environments. Meister Media Worldwide, Willoughby, $\mathrm{OH}$.

Di Gioia, F. and P. Santamaria. 2015. Microgreens: Microgreens in novel fresh and functional food to explore all the value of biodiversity. Eco-Logica, Bari, Italy.

Dorais, M., C.A. Mitchell, and C. Kubota. 2017. Lighting greenhouse fruiting vegetables, p. 159-165. In: R. Lopez and E. Runkle (eds.). Light management in controlled environments. Meister Media Worldwide, Willoughby, $\mathrm{OH}$.

Dou, H., G. Niu, M. Gu, and J.G. Masabni. 2017. Effects of light quality on growth and phytonutrient accumulation of herbs under controlled environments. Horticulturae 3:36-47.

Dou, H., G. Niu, M. Gu, and J.G. Masabni. 2018. Responses of sweet basil to different daily light integrals in photosynthesis, morphology, yield, and nutritional quality. Horticulturae 53:496-503.

Ehleringer, J.R. and D.R. Sandquist. 2010. Photosynthesis: Physiological and ecological considerations, p. 243-269. In: L. Taiz and E. Zeiger (eds.). Plant physiology. 5th ed. Sinauer and Associates, Sunderland, MA.

Fan, X.X., Z.G. Xu, X.Y. Liu, C.M. Tang, L.W. Wang, and X.L. Han. 2013. Effects of light intensity on the growth and leaf development of young tomato plants grown under a combination of red and blue light. Scientia Hort. 153:50-55.
Ferreira Fernandes, V., L.B. de Almeida, E.V.R. Feijó, D. Silva, R. de Oliveira, M.S Mielke, and L. Costa. 2013. Light intensity on growth, leaf micromorphology and essential oil production of Ocimum gratissimum. Rev. Bras. Farmacogn. 23: 419-424.

Frak, E., X. Le Roux, P. Millard, E Dreyer, G. Jaouen, B. Saint-Joanis, and R. Wendler. 2001. Changes in total leaf nitrogen and partitioning, of leaf nitrogen drive photosynthetic acclimation to light in fully developed walnut leaves. Plant Cell Environ. 24:1279-1288.

Gao, G., R. Becker, M. Brown, M. Ellis, S. Prochaska, C. Welty, and R. Williams. 2009. Midwest home fruit production guide: Cultural practices and pest management. 12 June 2019 . <https://ag. purdue.edu/hla/pubs/Midwest_Home_ Fruit_Production_Guide_940.pdf $>$.

Garden Media Group. 2017. State of the industry report: Trends. 2 Dec. 2018. <https://www.gardencentermag.com/ article/garden-media-groups-2018trends-report $/>$.

Gu, M., J.A. Robbins, C.R. Rom, and H. Choi. 2008. Photosynthesis of birch genotypes (Betula L.) under varied irradiance and $\mathrm{CO}_{2}$ concentration. HortScience 43:314-319.

Halleck, L.F. 2018. Gardening under lights: The complete guide for indoor growers. Timber Press, Portland, OR.

He, J., S.K. Lee, and I.C. Dodd. 2001. Limitations to photosynthesis of lettuce grown under tropical conditions: Alleviation by root zone cooling. J. Expt. Bot. $52: 1323-1330$

Jurik, T.W., J.A. Weber, and D.M. Gates. 1988. Effects of temperature and light on photosynthesis of dominant species of a northern hardwood forest. Bot. Gaz. 149:203-208.

Kalich, K., D. Bauer, and D. McPartlin. 2009. Cultivating healthy food choices in young children. Redleaf Press, St. Paul, MN.

Kang, J.H., K. Sugumaran, S.L. Sua Atulba, B.R. Jeong, and S.J. Hwang. 2013. Light intensity and photoperiod influence the growth and development of hydroponically grown leaf lettuce in a closed-type plant factory system. Hort. Environ. Biotechnol. 5:501-509.

Kortright, R. and S. Wakefield. 2011. Edible backyards: A qualitative study of household food growing and its contributions to food security. Agr. Human Values 20:39-53.

Lopez, R.G. and E.S. Runkle. 2008. Photosynthetic daily light integral during propagation influences rooting and growth of cuttings and subsequent development of new guinea impatiens and petunia. HortScience 43:2052-2059.

Majkowska-Gadomska, J., A. Kulczycka, A. Dobrowolski, and E. Mikulewicz. 2017. Yield and nutritional value of basil grown in a greenhouse. Acta Agrophysics. $24: 455-464$

McDonald, M.S. 2003. Photobiology of higher plants. Wiley, Chichester, UK.

Moccaldi, L.A. and E.S. Runkle. 2007. Modeling the effects of temperature and photosynthetic daily light integral on growth and flowering of Salvia splendens and Tagetes patula. J. Amer. Soc. Hort. Sci. 132:283-288.

Moya, E., C. Sahagún, J. Carrillo, P. Alpuche, C. Álvarez-González, and R. Martínez Yáñez. 2014. Herbaceous plants as part of biological filter for aquaponics system. Aquacult. Res. 47:1716-1726.

Nemali, K.S. and M. van Iersel. 2004. Acclimation of wax begonia to light intensity: Changes in photosynthesis, respiration, and chlorophyll concentration. J. Amer. Soc. Hort. Sci. 129:745-751.

Nobel, P.S., L.J. Zaragoza, and W.K. Smith. 1975. Relation between mesophyll surface area, photosynthetic rate, and illumination level during development for leaves of Plectranthus parviflorus Henckel. Plant Physiol. 55:1067-1070.

Oguchi, R., K. Hikosaka, and T. Hirose. 2003. Does the photosynthetic lightacclimation need change in leaf anatomy? Plant Cell Environ. 26:505-512.

Oh, W., E.S. Runkle, and R.M. Warner. 2010. Timing and duration of supplemental lighting during the seedling stage influence quality and flowering in petunia and pansy. HortScience 45:1332-1337.

Omobolanle Ade-Ademilua, E., H.O. Oghenekome, and L.E. Craker. 2013. Growth and essential oil yield of african basil, Ocimum gratissimum, under light and water stress. J. Medicinally Active Plants 1:143-149.

Park, K., K. Bekhzod, J.K. Kwon, and J.E. Son. 2016. Development of a coupled photosynthetic model of sweet basil hydroponically grown in plant factories. Hort. Environ. Biotechnol. 57:20-26.

Paz, M., P. Fisher, and C. Gómez. 2019. Minimum light requirements for indoor gardening of lettuce. Urban Agr. Reg. Food Systems. 4:1-10.

Peralta, G., J.L. Pérez-Looréns, I. Hernández, and J.J. Vergara. 2002. Effects of light availability on growth, architecture and nutrient content of the 


\section{Research Reports}

seagrass Zostera noltii Hornem. J. Exp. Mar. Biol. Ecol. 269:9-26.

Poulet, L., G. Massa, R.C. Morrow, C.M. Bourget, R.M. Wheeler, and C.A. Mitchell. 2014. Significant reduction in energy for plant-growth lighting in space using targeted LED lighting and spectral manipulation. Life Sci. Space Res. 2:4353.

Raimondi, G., F. Orsini, A. Maggio, S. De Pascale, and G. Barbieri. 2006. Yield and quality of hydroponically grown sweet basil cultivars. Acta Hort. 723:353-359.

Sims, D.A. and R.W. Pearcy. 1992. Response of leaf anatomy and photosynthetic capacity in Alocasia-macrorrbiza araceae to a transfer from low to high light. Amer. J. Bot. 79:449-455.

Somerville, C., M. Cohen, E. Pantanella, A. Stankus, and A. Lovatelli. 2014. Smallscale aquaponic food production: Integrated fish and plant farming. FAO Fish. Aquacult. Tech. Paper 589:1-288.

Terfa, M.T., K.A. Solhaug, H.R. Gislerød, J.E. Olsen, and S. Torre. 2013. A high proportion of blue light increases photosynthesis capacity and leaf formation rate of Rosa xhybrida but does not affect time to flower opening. Physiol. Plant. 148:146-159.

U.S. General Services Administration. 2013. Facilities standards (P100). 23 Jan. 2019. <https://www.gsa.gov/portal/ category $/ 21048 />$. van Iersel, M.W. 2017. Optimizing LED lighting in controlled environment agriculture, p. 59-80. In: S.D. Gupta (ed.). Light emitting diodes for agriculture: Smart lighting. Springer Nature, Singapore.

von Caemmerer, S. and G.D. Farquhar. 1981. Some relationships between the biochemistry of photosynthesis and the gas exchange of leaves. Planta 153:376387.

Walters, K.J. and C.J. Currey. 2018. Effects of nutrient solution concentration and daily light integral on growth and nutrient concentration of several basil species in hydroponic production. HortScience 53:1319-1325.

Yamashita, N., A. Ishida, H. Kushima, and N. Tanaka. 2000. Acclimation to sudden increase in light favoring an invasive over native trees in subtropical islands. Jpn. Oecologia 125:412-419. 